\title{
The Development of a Language-and-Culture Course Incorporating Intercultural Teaching Materials in the Tunisian Higher Education EFL Context: Challenges and Opportunities
}

\author{
Anouar Smaoui ${ }^{1,2}$ \\ ${ }^{1}$ English Language Unit, Faculty of Science of Sfax, University of Sfax, Sfax, Tunisia \\ ${ }^{2}$ General Required Courses Department, Faculty of Applied Studies, King Abdul Aziz University, Jeddah, KSA \\ Email: anouarsmaoui@ymail.com
}

How to cite this paper: Smaoui, A. (2021). The Development of a Language-and-Culture Course Incorporating Intercultural Teaching Materials in the Tunisian Higher Education EFL Context: Challenges and Opportunities. Open Journal of Modern Linguistics, 11, 1-23.

https://doi.org/10.4236/ojml.2021.111001

Received: November 3, 2020

Accepted: January 17, 2021

Published: January 20, 2021

Copyright $\odot 2021$ by author(s) and Scientific Research Publishing Inc. This work is licensed under the Creative Commons Attribution International License (CC BY 4.0).

http://creativecommons.org/licenses/by/4.0/

\begin{abstract}
Little data is currently available on course and materials design for intercultural competence (IC) teaching in the Tunisian higher education EFL context. The present study aimed to investigate these issues with reference to current literature on intercultural course and materials development as well as instructional design and affordance theories. In particular, it explored the potential development of an intercultural training course consisting of teaching materials that employ three types of teaching techniques, namely the cultural awareness technique (CAT), critical incident technique (CIT) and cultural misunderstanding technique (CMT). The result was a comprehensive course that included attainable goals, realistic learning objectives, conducive learning experiences, along with clear assessment criteria, scales, descriptors, methods, and tools for gauging the attainment of achievable learning outcomes. The findings reported in this work are particularly interesting for they could form a critical foundation for further research on the intercultural dimension in various higher education EFL contexts and a tentative blueprint for potential future work on intercultural curriculum, syllabus, course, and/or teaching materials development.
\end{abstract}

\section{Keywords}

Constructive Alignment, Instructional Design, Intercultural Dimension, Teaching Materials, Internationalization of Higher Education

\section{Introduction}

Intercultural competence (IC) is increasingly recognized as a central criterion for 
successful communication across the growingly interconnected contemporary world. Higher education institutes (HEIs), worldwide, have realized the pressing need to introduce the intercultural dimension in their mission to help students to become effective global citizens. The literature presents a multitude of frameworks and models for the teaching and assessment of IC. During the 1980's, the American Council on the Teaching of Foreign Languages (ACTFL) and in response to the growing interests in learners' global competence as an outcome of FL learning experiences issued a number of revolutionary guidelines to expand the scope of FL education to include culture learning and assessment (Kramsch, 1993). This is evidenced in the addition of cultural understanding to the National Standards for Foreign Language Education (ACTFL, 1996). The Proficiency Guidelines (2014) and Performance Descriptors for Language Learners also provide the criteria, scales and descriptors for intercultural communication skills using can-do statements that reflect learners' growth continuum through Novice, Intermediate, Advanced, Superior, and Distinguished levels.

In the same vein, the Council of Europe and European Centre for Modern Languages (ECML) responded to the growing interests in intercultural competence learning and assessment and sought coherence in the European context. This is evidenced in the publication of the Common European Framework of Reference (CEFR, 2001), a document that has the promotion of plurilingual and intercultural education as a major concern. The CEFR has been adopted as the standard for learning outcomes at different levels of education, from primary through secondary to higher education contexts across Europe and beyond. The CEFR also presents a comprehensive illustrative assessment scheme and a set of reference descriptions. It has been adopted as a reference model for defining learning objectives and assessing student learning outcomes. Interculturalists working within the ECML framework, built on the criteria, scales and descriptors presented in the CEFR and drew on Byram's (1997) multidimensional IC model to produce practical IC assessment tools with scalable descriptors. These included the "Intercultural Competence Assessment" (INCA), the "Autobiography of Intercultural Encounters" (AIE), the WebCEF, the CEFcult, the "Competences for Democratic Culture" (CDC), the "Language On Line Portfolio Project" (LOLIPOP), and the "Intercultural Dialogue" (ID) projects.

Although the intercultural dimension is not new to the academic and professional context in Tunisia, this concept has not surfaced to the Tunisian EFL research until the last two decades (Smaoui, 2020). This arose from the increasing awareness within the Tunisian education industry of the urgent need to address the linguistic implications of internationalization on the Tunisian EFL context (Smaoui, 2020). However, and to the author's knowledge, no studies have so far been performed to explore intercultural course and materials development in the Tunisian EFL context. The studies currently available dealt with teacher and learner cognition and attitudes (Hermessi, 2016; Rahal, 2017); the place of culture in Tunisian EFL textbooks (Abid, 2018; Abid \& Moalla, 2020; Hermessi, 2017), and the effects of teaching materials (TM) on students' IC learning (Arfi \& Hanna- 
chi, 2016; Horchani \& Hosni, 2012; Mason, 2010). Of particular interest, although teaching materials (TM) have often been reported to play a promising inductive role in the learning process, little data is currently available on this issue in the Tunisian higher education EFL context (Smaoui, 2020). Moreover, and despite the growing interests worldwide in the development of glocal approaches to IC teaching and assessment, no work has so far been reported to investigate this tendency within the Tunisian EFL context (Smaoui, 2020). Of particular relevance, little work is currently available on the effectiveness of particular teaching content and/or material in the enhancement of IC development in the research context under investigation (Mason, 2010).

Furthermore, EFL teachers, in Tunisia and worldwide, need a wide range of educational tools and resources to support them throughout the instructional process, including TM and assessment strategies that fit well with their respective EFL contexts. In fact, the socio-cultural and pragmatic aspects of language teaching and learning have long been considered central in the EFL curricula at the research context of the present study, especially that Tunisian HEIs have had a long tradition in teaching beyond linguistic competence. By extension, the latter had a large student population majoring in English, for whom the socio-cultural and pragmatic aspects of language are of paramount importance. Accordingly, and motivated by the scarcity of data on intercultural course and TM development in the Tunisian higher education EFL context, this study aimed to take this strand of research on board and, in particular, explore the potential development of an intercultural training course for implementation and evaluation in terms of effectiveness in enhancing IC development in Tunisian higher education EFL learners.

\section{Research Design and Theoretical Framework}

The present work is the second phase of a broader three-phase mixed-method exploratory study wherein the researcher aimed to investigate the effectiveness of an intercultural training course employing three types of teaching techniques, namely the cultural awareness technique (CAT), critical incident technique (CIT) and cultural misunderstanding technique (CMT), in the enhancement of IC development in Tunisian higher education EFL students. The study employed a sequential three-phase design wherein the data collected in one phase informed the subsequent phase. The first phase was exploratory in nature and sought to identify the current learning context and learner needs in the Tunisian higher education context prior to embarking on a pedagogical intervention (Smaoui, 2020). The second phase (the present work) built on data reported on in the development phase as well as those currently available in the literature to develop a training course consisting of culture-informed materials for use in a subsequent training intervention. The final phase reports on the implementation and evaluation of the intercultural training intervention in terms of its effectiveness in enhancing IC development in an experimental group of Tunisian higher education EFL students (Smaoui, forthcoming). 
The research design of the present study aimed to identify: 1) the key dimensions of IC teaching and assessment within the local context against the framework developed through the existing literature; 2) an appropriate framework for the development of a glocal approach for IC teaching and assessment; and 3) the opportunities and challenges related to the process of developing an intercultural training course and TM with a glocal approach. The identification of those aspects is deemed essential for a principled approach to the development of an appropriate intercultural training course that meets the local context and serves the aims of the study. The following sections will be devoted to delineating the conceptual aspects pertaining to IC teaching and assessment.

\subsection{Conceptualization of IC}

The literature indicates that IC has been conceptualized under different names and taxonomies. Sercu (2005) provides a comprehensive review and concludes that IC has been defined from different perspectives and under relatively comparable terms, including, "transnational competence", "trans-cultural competence", "multicultural competence", "cross-cultural effectiveness", "intercultural sensitivity", and "global competency". She argues that despite the fundamental differences, most models include three common key dimensions, namely the cognitive (knowledge), affective (attitudes), and behavioral (skills) dimension of the construct. Two of the influential models, namely Byram's (1997) and Deardorff's (2006) models, will be described below.

\subsubsection{Byram's Multidimensional Model}

Following Byram (1997: p. 33), IC can be defined as the "ability to negotiate and mediate between multiple identities and cultures". Analyzing the dynamics of intercultural communication, interculturalists often agree that IC encompasses a complex set of three interrelated and synergistic components, namely the cognitive (knowledge), affective (attitudes), and behavioral (skills) domains (Risager, 1991; Deardorff, 2006; Paige et al., 1999). Byram (1997) organizes the three domains of IC in a conceptual framework comprising five interrelated components termed as know-hows, namely knowledge, attitudes, skills of interpreting and relating, skills of discovery and interaction, and critical cultural awareness.

Byram's (1997: pp. 34-53) defines the first component of IC, "knowledge", as a set of two broad categories. The first category pertains to "knowledge about social groups and their cultures in one's own country, and similar knowledge of the interlocutor's country". The second category relates to "knowledge of the processes of interaction at individual and societal levels". He maintains that each category entails both culture-specific (of one's own and foreign cultures) and culture-general knowledge. The second component of IC is "attitudes". These are defined as one's empathetic understanding of cultural phenomena, and capacities to "see the world through someone else's eyes". He defines empathy as having two facets. The first relates one's ability to "decentre"; the second involves an insider's knowledge of the value and belief systems that lie behind dif- 
ferent perspectives; that is the perspective of the foreign culture. The third component relates to "the skills of interpreting and relating", defined as the "ability to interpret a document or event from another culture, to explain it and relate it to documents from one's own". According to him, this skill draws upon existing knowledge and "can be distinguished from the skill of discovery and interaction in that it need not involve interaction with an interlocutor, but may be confined to work on documents". The fourth component relates to the "skills of discovery and interaction". Byram (1997: pp. 35-38) defines them as the "ability to acquire new knowledge of a culture and cultural practices and the ability to operate knowledge, attitudes and skills under the constraints of real-time communication and interaction". An individual having the skills of discovery is an individual who has "the ability to recognize significant phenomena in a foreign environment and to elicit their meanings and connotations, and their relationship to other phenomena". These skills are needed in interaction with people or work on documents in situations where the individual has little prior knowledge of the foreign culture phenomena and their significance or meanings. Finally, Byram (1997: p. 53) holds that, in an educational setting where the intercultural teaching is embedded within a philosophy of political education, the intercultural speaker must also develop the fifth component of IC, namely "critical cultural awareness". This is defined as the "ability to evaluate critically and on the basis of explicit criteria perspectives, practices and products in one's own and other cultures and countries".

\subsubsection{Deardorff's Process Model}

Deardorff (2006: p. 194) defines IC as the "effective and appropriate behavior and communication in intercultural situations". She proposes a Process Model wherein IC is seen as an interplay between personal and interpersonal elements, categorized under knowledge, skills, and attitudes, as well as internal and external attributes. In its essence, the model suggests that the lower levels (Attitudes, Skills, and Knowledge) enhance the effectiveness of the upper levels (Internal and External Outcomes). The basic assumption of the model is that it is through the development of knowledge, skills, and attitudes that the learner is led to the internal outcome (empathy, adaptability, and flexibility). The internal outcome then facilitates the external outcome of "behaving and communicating effectively and appropriately" (Deardorff, 2006: p. 254). According to the Process Model, IC learning is a developmental ongoing cyclical transition from knowledge through attitudes and skills to intrinsic and extrinsic changes in the intercultural domain (Deardorff, 2006). At the internal level, learners would become more empathetic and flexible, and at the external level, their behaviors would be more effective.

\subsection{The Integration of IC in FL Curricula}

The literature indicates that intercultural curriculum development (CD) is a complex decision-making process that involves strategic considerations to several in- 
terdependent factors. The degree of success of a language curriculum is reported to depend on the informed alignment of different elements, namely the 1) goals, 2) content, 3) instructional design, 4) tasks, 5) roles 6) affordances, and 7) assessment (Biggs, 2003; Biggs \& Tang, 2011). The position most strongly defended in the literature is that rather than using one-size-fits-all instructional packages available for the international market, intercultural courses and TM should be produced to fit the context they are meant to serve (Kramsch, 1993; McKay, 2003). Several interculturalists advocate a "glocal" approach to course and TM design, wherein global perspectives are blended with the local context. McKay (2003: p. 140), for instance, encourages teachers to think globally but teach locally, and argues for the contextualization of English to the local EFL context.

A thorough survey of the literature reveals that several communities have adopted a "think globally, teach locally" approach. Within the context of the Council of Europe, the work of Byram and his coauthors has been influential in the production of several textbooks, including Mirrors and windows: An intercultural communication textbook (Huber-Kriegler et al., 2003) and Plurilingual and intercultural learning through mobility: Practical resources for teachers and teacher trainers (Cuenat et al., 2015). Within the British Council context, the work of Pulverness and his colleagues have strongly supported the development of several textbooks, including Zoom In (Hungary), Branching out (Bulgaria), Crossing Cultures (Romania), Lifestyles (Czech Republic), Changing Skies: The European Course for Advanced Level Learners (Central and Eastern Europe), and British Studies: Materials for English Teachers (Poland). Within the American context, Seelye's (1997) Teaching Culture Strategies for Intercultural Communication, and Fantini's (1997) New Ways in Teaching culture, are two examples of local productions for integrating culture in language teaching. Other publications within the Peace Corps context include cross-cultural textbooks by Storti \& BennholdSamaan (1997) and his coauthors, such as Culture Matters, Building Bridges, Looking at Ourselves and Others, Uncommon Journeys, Voices from the Field, and Insights from the Field.

\subsubsection{Defining the Learning Context and Learner Needs}

As has often been the case in the teaching enterprise, the identification of learner needs and the learning context is a crucial step in course and TM design (Hutchinson \& Waters, 1987; Brown, 1995; Brindley, 1984; West, 1997). The literature indicates that needs analysis (NA) is an umbrella term used to describe the collection and analysis of formal or informal data on the learners and the learning context. These include several influential components, including the institutional, educational, administrative, political, and socio-cultural elements (Brown, 2009). West (1997: pp. 71-74) lists nine different types of NA, namely, targetsituation, deficiency, present-situation, learning-oriented, strategy, means, language audit, set menu, and computer-based analyses. Brindley (1984, p. 28) adds other types of NA, including wants, desires, demands, expectations, motivations, 
lacks, constraints, and requirements analyses. Overall, educationalist conducting NA research seem to use different combinations of some of these alternative types of information depending on the aims and objectives of their respective works.

As far as the Tunisian EFL context is concerned, the present study builds on data reported in a previous work by the author on the learning context and learner needs of the research site (Smaoui, 2020) and in previous studies on the intercultural dimension in the Tunisian EFL context (Hermessi, 2016, 2017; Rahal, 2017; Abid, 2018; Abid \& Moalla, 2020; Arfi \& Hannachi, 2016; Horchani \& Hosni, 2012; Mason, 2010). Smaoui (2020) used informal group discussions, semi-structured interviews and questionnaires among student and teacher participants from a Tunisian higher education EFL institute and reported that both the teachers and student respondents were predisposed to the introduction of the intercultural dimension to EFL education. The results also indicated that student respondents generally displayed a narrow surface-level and reductionist understanding of culture that equates culture with nations, as opposed to the broad deep-level understanding displayed by teachers. Student participants were noted to refer essentially to observable "Big C" elements, such as family life, famous people and popular events with little to no reference to the less observable "small c" aspects of culture, including the norms, beliefs, and values. Abid (2018) investigated a corpus of Tunisian EFL textbooks and teachers' and learners' perceptions of local and global identities and the potential that Tunisian EFL classes could have for developing learners' local and global identities. She concluded that current Tunisian EFL classes have little potential for the development of a sense of belonging neither to the local nor to the global communities, which might have negative effects on learners' perception of themselves as members of both their nation and the world. Hermessi (2017) conducted a document analysis that evaluated a number of local official curricular documents, textbooks, and teacher guides for Tunisian basic and high schools in terms of theoretical references and actual realizations of cultural content. The study revealed that although Tunisian language policymakers have no apparent ideological objections to the incorporation of culture in EFL education, they do not approach culture teaching in a principled systematic way. The results also indicated that there exists no clear theoretical or pedagogical frame of reference to culture teaching in the Tunisian EFL context.

\subsubsection{Defining the Goals and Objectives of IC Teaching and Learning}

The literature indicates that the successful integration of IC in any educational program relies primarily on the clear, precise and comprehensive translation of the three IC domains, namely the cognitive (knowledge), behavioral (skills) and affective (attitudes) dimensions, into achievable aims and objectives (Byram, 1997; Paige et al., 1999; Fenner \& Newby, 2000). Paige et al. (1999) suggests that IC based programs work on the three domains of IC and track learners' progress at different points along a developmental continuum. He adds that the three di- 
mensions should include both culture-specific and culture-general forms of learning and teaching. Culture-specific forms emphasize elements of knowledge and skills relevant to a specific target culture, i.e. a particular culture group or community. Culture-general forms, on the other hand, emphasize the teaching of the knowledge and skills that are more generalizable in nature and transferable across cultures.

The cognitive orientation of educational programs relates to one's knowledge of the self, of the other, and of interaction. In particular, this entails a cognitive awareness of both culture-specific (of one's own and foreign cultures) and culture-general knowledge necessary for successful intercultural communication, interaction, and mediation. Culture-specific knowledge involves aspects from "small c" target culture knowledge (food, clothes, etc.) and "big C" target culture knowledge (values, beliefs). Culture general knowledge relates to the degrees to which students are able to explain factual knowledge and its significance from within the cognitive perspective of the foreign culture.

The attitudes orientation involves culture-general attitudes (positive attitudes towards other cultures and culture learning) and culture-specific (positive attitude towards the target culture and its people). Language programs should encourage learners to look at their own familiar culture from another perspective and learn to empathize with and show respect for otherness in general. More succinctly, attitudes involve the ability to "decenter" affectively; that is, to "relativize oneself" (one's values, beliefs, and behaviors within a larger perspective) and to value others' values, beliefs and behaviors.

The behavior orientation involves "culture-general skills" and "culture-specific skills". The former covers all forms that equip individuals to communicate effectively in intercultural encounters and to resolve conflict where necessary. The latter covers both "little c" behavior (appropriate everyday behavior) and "big C" behavior (appropriate contextual behavior).

\subsubsection{Defining Cultural Content}

Tomlinson (2008, 2010, 2012) and Tomlinson \& Masuhara (2010) describe TM development as a complex process that involves the production and/or use of materials for language learning, including the representation of local versus target culture(s) in TM, the selection and sequencing of cultural content in TM, and the incorporation of cultural topics and teaching techniques in lesson design. Fenner \& Newby (2000) and Skopinskaja (2003) maintain that in modern foreign language teaching (FLT), the definition of cultural content in textbooks and TM must become as important as the linguistic content. Byram (1989: p. 3) shares a similar view and highlights that the cultural content should not be "incidental to the real business of language teaching", explaining that the choice of cultural topics, activities and tasks should depend on the educational context in which the FL is taught, the learners, and the teacher.

\subsubsection{Defining Teacher and Learner Roles}

The theoretical framework presented above clearly indicates that the promotion 
of IC learning is highly influenced by both the teacher and the learner. The centrality of teacher roles touches upon several aspects pertaining to Sercu's (2005) composite term "foreign language and intercultural competence teachers" and to what Byram (1989) calls "the language teachers as teachers of culture". Discussions have often revolved on how teachers structure the learning experiences, contribute to the learning process, demonstrate culture to learners, control the learning tasks and activities, and monitor learners' development towards autonomy. From this perspective, teachers should be prepared to assume various roles, including those of the ethnographer, awareness-raiser, supporter, facilitator, mediator, animator, advisor, sensitizer, counselor, assessor, and evaluator (Sercu, 2002; Kramsch, 1993).

The significance of learner roles in intercultural education has also been equally emphasized in the literature. It also relates to multiple facets, including how learners contribute to the learning process, control the learning process, and progress towards autonomous lifelong learning. From this perspective, learners should be able to function as objectives-planners, ethnographers, culture-explorers, communication-seekers, initiative-takers, actors, cooperators, mediators, difference-acceptors, development controllers, self-evaluators, and self-assessors (Sercu, 2002; Kramsch, 1993).

\subsubsection{Defining Instructional Design}

The principle of instructional design (ID) is central to CD (Biggs, 1996; Biggs \& Moore, 1993; Biggs \& Tang, 2011; Young, 2009). Following Biggs \& Moore (1993), ID can be defined as the systematic design, development and evaluation of a flexible instructional delivery system, including learning activities, resources, and procedures, to support student learning and ensure the quality and equity of the learning experience. It encompasses the entire process of analysis of students' sociocultural backgrounds, learning styles, learning needs and goals, and the development of a relevant and meaningful instructional delivery system that best meets the profile of that particular learner community (Briggs, 1977; Briggs et al., 1991; Gagne et al., 1992). It includes the development of various practice elements, including learning materials, tasks, activities, and medium of instruction (including technology), which facilitate active learning and engagement (Briggs et al., 1991; Gagne et al., 1992). The difference between ID and CD lies in the fact that while $\mathrm{CD}$ requires specialists and experts in a particular subject matter, ID requires experts in physical and virtual learning environments that foster learning across the disciplines. ID experts build on learning theories and design instructional products that facilitate learning. Conventional ID includes the design of case-based, problem-based, and project-based instructional products; more recent ID includes the production of educational technologies, such as educational software, Web-based environments, videos, and films. The basic aim of constructing an ID is to create a product that helps fulfill the intended learning outcomes.

The techniques and activities proposed for the facilitation of IC learning ab- 
ound in the literature. The present work highlights three techniques, namely the culture awareness technique (CAT), the cultural misunderstanding technique (CMT) and the critical incident technique (CIT). This work considers those techniques relevant for IC development and assessment in the Tunisian higher education context, particularly because they can be adopted in a variety of teaching and assessment purposes. Chastain (1988: p. 311) defines the CAT as a consciousness-raising technique that aims to raise students' consciousness of the hidden beliefs that direct their own values, attitudes, and actions. According to Feng \& Byram (2002) CAT can be of two types, culture-specific and culture-general. Culture-specific CAT is specific to a culture or area; it can teach a range of information such as factual background data, famous people and popular food in the country or culture. Culture-general CAT deals with deeper invisible topics such as the values, beliefs, norms that influence communication. The CAT may take the form of various activities, including quizzes, self-assessment questionnaires, problem-solving exercises and checklists of value, attitude, or action orientations (Chastain, 1988).

The second technique, CMT, is described by Brislin (1995) as an awarenessraising technique that employs a problematic situation embodying a case of an unintentional misunderstanding, problem, or conflict, rising from good-natured ignorance of cultural differences between interacting parties, one of whom is a foreigner. It presents the problematic situation and requires learners to identify the problem and its underlying causes. Feng \& Byram (2002) recommend the presentation of situations involving cultural misunderstandings, which in real life would cause one or more of the interlocutors to become confused, angry, or even offended. They propose various activities from the CMT type, including problem-solving exercises, attitude or action orientation exercises, comparisons and contrasts, group discussions, and role-plays.

The third technique, CIT, is defined by Baxter \& Ramsey (1996: p. 211) as "a segment of observed human behavior which by itself permits inferences to be made about the people involved in it". Critical incidents are sometimes used synonymously with culture misunderstandings. There are, however, major differences between the two techniques (Cushner \& Brislin, 1996; Seelye, 1996; Pusch, 1996). The CIT usually requires students to read the incident independently and to make individual reactions and decisions. They are then put into small groups to discuss their findings. A classroom discussion follows where students try to give reasons behind the reactions or decisions being made. Finally, students are given the opportunity to see how their decision and reasoning compare and contrast with the decisions and reasoning of native members of the target culture.

\subsubsection{Defining Affordances for Learning}

Drawing on Doering et al. (2008), affordance is taken to designate the usability of a tool offered to learners by an object in the environment to accomplish a type or some types of learning. Boyle \& Cook (2004) provide a comprehensive review 
of the concept of affordances and argue that much of student learning relies heavily on the availability of the tool. The literature presents various types of affordances, including socio-cultural, educational, and technological affordances (Doering et al., 2008; Boyle \& Cook, 2004). Recent research has become particularly interested in exploring the powerful affordances of technology and the rich opportunities it offers for enhancing the learning experience. Teachers have often been encouraged to conduct an affordance analysis so as to make use of the affordances that support the learning experience and avoid the ones that hinder or impair it. Teachers need to identify the affordances that best match the requirements of the various learning tasks and activities they deem important for facilitating learning.

\subsection{IC Assessability}

Deardorff $(2006,2009)$ conducted extensive research on IC development and assessment and identified several gaps and challenges that hamper the instrumentation and operationalization of IC assessment, including the absence of consensus on the formulation of clear achievable learning outcomes (LOs). She argues that assessment is a complex process that involves gathering and discussing information from multiple sources to develop a deep understanding of what learners know (cognitive), understand/value (affective) and can do with their knowledge (behavioral) as a result of their educational experiences. She suggests that the first step in the LOs formulation process consists in defining the construct of interest and its components. The latter would constitute the criteria for assessment. The operationalization of assessing the construct of interest needs the articulation of what learners are intended to know (cognitive/knowledge domain), understand/value (affective/attitudes domain), and can do (behavioral/psychomotor/skills domain). Once the construct and its constituents have been defined, teachers can use the learning goals as aspects of performance (criteria); identify the performance levels for each goal (scale); delineate the characteristics associated with each criterion and scale (descriptors); and decide on the appropriate assessment methods and strategies (tasks/activities).

\subsubsection{Defining Learning Outcomes: Criteria}

Learning outcomes (LOs) have often been defined as statements indicating what a learner is expected to know (cognitive/knowledge), understand and value (affective/attitudes) and can do (behavioral/ skills) at the end of a learning experience (Bloom, 1956; Anderson \& Krathwohl, 2001). Interculturalists generally classify learning outcomes into general and specific outcomes. General outcomes refer to broad statements identifying the knowledge, skills, and attitudes that learners are expected to achieve during a learning experience. Each general outcome is further broken down into specific outcomes that learners are expected to achieve by the end of a learning experience. Specific learning outcomes have often been further categorized by strands that indicate the developmental flow of learning from the basic to the advanced cycles of learning. 
Drawing on Byram's (1997) multidimensional model for IC, the authors of the Intercultural Competence Assessment (INCA, 2004) project describe IC as consisting of three broad strands (openness, tolerance of ambiguity, and adaptability), each comprising two constituents, thus forming a total of six dimensions. These strands are described in Table 1.

\subsubsection{Defining Performance Levels: Scale}

Byram and his INCA project partners define three tentative levels, namely "basic", "intermediate", and "full", to indicate the level that an individual has developed and put into action in a particular response to a given assessment item in terms of each of the six constituents. The three levels are presented in Table 2.

\subsubsection{Defining Characteristics Associated to the Criteria and Levels: Descriptors}

To make assessment manageable and effective, the authors of the INCA project translate each of the six dimensions of IC into concrete descriptors for use during the assessment of a particular assessment item. Evaluators use assessment sheets that contain three columns representing the three major levels of performance, namely "basic", "intermediate" and "full level". The columns in the sheet contain examples describing the participant's skill level. The responses of the assessee to a particular assessment item are dissected and analyzed based on criterion-referenced descriptors, assigned to one of the skill levels, and ticked off to

Table 1. The three strands and six constituents of IC (INCA, 2004: p. 11).

\begin{tabular}{|c|c|}
\hline openness & $\begin{array}{l}\text { - Respect for otherness: } \\
\text { ability to look at all customs and values from a distance, regarding them at } \\
\text { the same time as worthwhile in their own right) } \\
\text { - Tolerance of ambiguity: } \\
\text { ability to accept ambiguity and lack of clarity and deal with it constructively }\end{array}$ \\
\hline knowledge & $\begin{array}{l}\text { - Knowledge discovery: } \\
\text { ability to acquire and actually use cultural knowledge } \\
\text { - Empathy: } \\
\text { ability to intuitively understand what other people think and how they feel }\end{array}$ \\
\hline adaptability & $\begin{array}{l}\text { - Behavioral flexibility: } \\
\text { ability to adapt one's own behavior to different requirements and situations } \\
\text { - Communicative awareness: } \\
\text { ability to identify and consciously work with communicative conventions }\end{array}$ \\
\hline
\end{tabular}

Table 2. The three levels of IC (INCA, 2004: pp. 7-8).

\begin{tabular}{cl}
\hline Basic competence: & $\begin{array}{l}\text { Individual is reasonably tolerant, willing to interact successfully } \\
\text { but responds only to events instead of planning for them; }\end{array}$ \\
$\begin{array}{c}\text { Intermediate } \\
\text { competence: }\end{array}$ & $\begin{array}{l}\text { Individual prefers responding in a neutral way to difference, and is } \\
\text { prepared to respond and adapt to the demands of unfamiliar situations; }\end{array}$ \\
Full competence: & $\begin{array}{l}\text { Individual is confident enough of his/her own position in order to take } \\
\text { a polite stand over issues and is constantly ready to use a large repertoire } \\
\text { of strategies, knowledge, and skills to deal with difference. }\end{array}$
\end{tabular}


indicate frequency (next to "full competence" if the answer indicates that the participant possesses that particular skill, next to "basic competence" if the answer indicates a low level of that particular skill, etc.). The overall skill level is determined for each skill by examining all the responses marked on the assessment form and assigning a total score by putting an " $\mathrm{X}$ " on the skill level score, whether a basic, intermediate, or full skill level (1, 2, 3, respectively). Following agreement on a final result for each assessee by a committee of assessors, feedback is given for the assessee in the form of final rating results for the 3 strands of competences. Table 3 provides descriptors for each level of the first dimension, tolerance for ambiguity.

\subsubsection{Defining the Methods of IC Assessment}

The complexity with which the development of a comprehensive IC assessment framework stems from the variety of contexts and disciplines in which IC theory and research were based and from the different foci and purposes they were meant to fulfill. Complexity also revolves around complex dichotomies in conceptualization and approach, including quantitative vs. qualitative, direct vs. indirect, formal vs. informal, formative vs. summative, and holistic vs. analytic to mention only a few (Verjans et al., 2011). The result is a wide range of different assessment models. Sinicrope et al., (2007) review the major IC assessment models available in the literature, including the Cross-Cultural Adaptability Inventory (CCAI) (Kelley \& Meyers, 1992), the Intercultural Sensitivity Scale (ISS) (Chen \& Starosta, 1996), the Intercultural Developmental Inventory (IDI) (Hammer et al., 2003), the Your Objectives, Guidelines, \& Assessment (YOGA) (Fantini \& Tirmizi, 2006), and the Intercultural Competence Assessment (INCA, 2004).

For the sake of brevity and simplicity, the present study draws on three types of assessment as described by Stiggins (2001) and Earl (2003). The first type is assessment FOR learning (AFL), which occurs when teachers use inferences about student knowledge, understanding and skills to inform their teaching. The

Table 3. Descriptors for each level of the dimension of tolerance for ambiguity (INCA, 2004: p. 9).

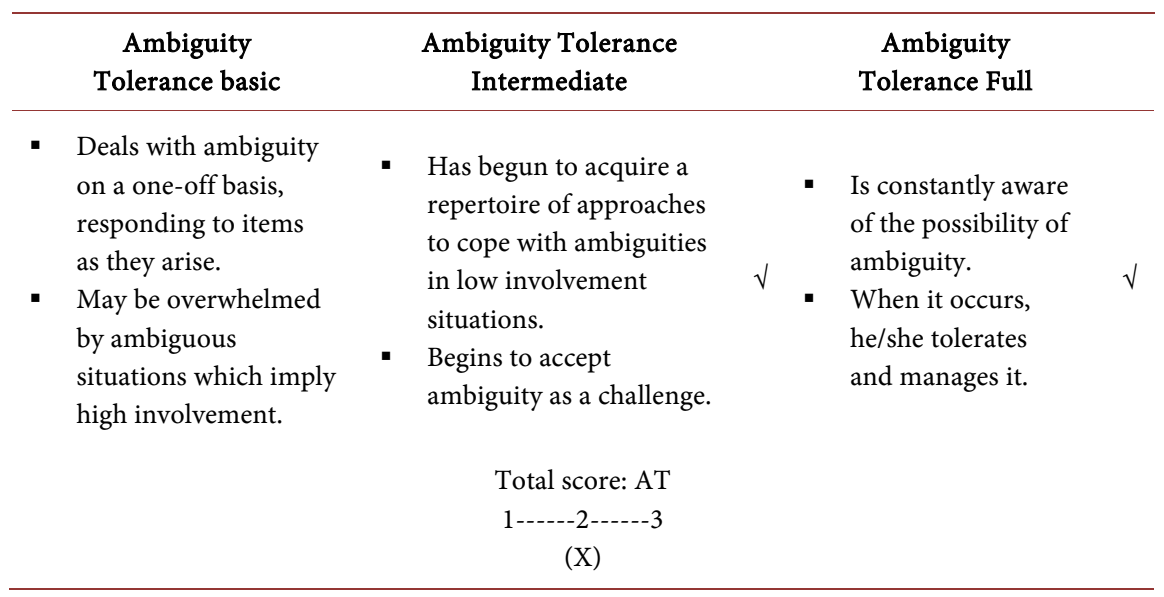


second type, assessment AS learning (AAL), occurs when students reflect on their learning and work towards learning goals. The third type, referred to as assessment OF learning (AOL), occurs when teachers use evidence of student learning to make judgments on student achievement against learning goals and standards. Stiggins (2001) argues for a balanced approach wherein teachers need to involve their students in classroom assessment, record-keeping, and communication throughout the learning experience and takes the lead in conducting assessments of learning when the educational system requires the students to be accountable for what they have learned.

\subsubsection{Defining the Instruments and Tools of IC Assessment}

Byram (1997) suggested the use of observation, questionnaires, tests, diaries, self-reports, and interviews as tools for IC assessment. Feng \& Byram (2002) and the contributors to the INCA (Prechtl \& Davidson-Lund, 2007) and CEFcult (Beaven \& Livatino, 2012) projects propose various types of techniques and activities for the assessment of intercultural skills, including questionnaires, scenarios, and role-plays. The activity types used under the scenario techniques reflect the three types of techniques described earlier, namely the CAT, CMT, and CIT.

\section{Results}

This work is an attempt to develop a tentative framework for a general languageand-culture training course incorporating intercultural TM. It builds on data previously reported on the learning context and learner needs of the study (Smaoui, 2020) and on the intercultural dimension in the Tunisian EFL context (Hermessi, 2016, 2017; Abid, 2018; Mason, 2010). It also draws on the theoretical background of IC learning and teaching and the conceptual framework related to intercultural course and TM development.

\subsection{Course Specifications}

Considering the research objectives of the study (Section 1) and the theoretical framework of IC as well as the learning context and learner needs of the present work (Section 2.2.1), a tentative intercultural training course was developed as a part of a critical reading and writing course with the general goal of promoting students' critical reading and writing competence in ways that prepare them to become intercultural speakers or mediators who are able to engage with complexity and multiple identities and to avoid the stereotyping which accompanies the perception of someone through a single identity (Section 2.2.2). The general goal was then broken down into learning outcomes, which were constructed as a taxonomy of what students were expected to know, understand, and do after the completion of the training course. They consisted of observable and measurable statements on what the students were expected to attain in terms of the three IC dimensions of knowledge, attitudes, and skills upon course completion.

The next step was to develop a set of related observable and measurable learning objectives that reflected the learning outcomes in terms of the three strands of 
IC, namely knowledge, skills, and attitudes. The "knowledge" (cognitive) orientation of the course focused on the development of students' knowledge of social groups and their products and practices in one's own and in one's interlocutor's country, and of the general processes of societal and individual interaction. The attitudes component (affective) focused on the development of curiosity \& openness, readiness to suspend disbelief about other cultures and belief about one's own. The skills (behavioral) orientation focused on the development of two aspects. The first was the skills of interpreting \& relating, namely the ability to interpret a document or event from another culture, to explain it and relate it to documents or events from one's own. The second was the skills of discovery and interaction, namely the ability to acquire new knowledge of a culture and cultural practices and the ability to operate knowledge, attitudes, and skills under the constraints of real-time communication and interaction.

Two specific learning objectives were included under each strand. The learning objectives for the knowledge component of IC learning included knowledge of 1) the processes and institutions of socialization in one's own and in one's interlocutor's country; and 2) institutions, and perceptions of them, which impinge on daily life within one's own and in one's interlocutor's country and which conduct and influence relationships between them. The learning objectives for the attitudes component of IC learning included 1) willingness to seek out or take up opportunities to engage with otherness in a relationship of equality, distinct from seeking out the exotic or to profit from others; and 2) interest in discovering other perspectives on interpretation of familiar and unfamiliar phenomena both in one's own and in other cultures and cultural practices. The learning objectives for the skills component of IC learning included the ability to 1) identify areas of misunderstanding and dysfunction in an interaction and explain them in terms of each of the cultural systems present; and 2) elicit from an interlocutor the concepts or values of documents or events and develop an explanatory system susceptible of application to other phenomena. The three strands of competences and six objectives used in the present study are presented in Table 4.

Drawing on Byram's cultural content selection criteria (section 2.2.3), the teaching content selected for inclusion in the TM to achieve those six objectives focused primarily on six topics dealt with from both the local and global/target cultures: 1) Values, norms and beliefs, 2) Cultural contact, 3) Customs and traditions, 4) Marriage, 5) Prejudices and stereotypes, and 6) Ethnography. The learning tasks used to explore the six topics were designed to support student learning in a dynamic cooperative experiential learning environment. Therefore, students' engagement in classroom discussions, pair work and group work and involvement in peer feedback were expected as part of each learning task. In brief, the researcher sought to encourage the teacher and student roles described in the theoretical framework presented above (Section 2.2.4).

The researcher then considered the ways instructional design could facilitate learning (Section 2.2.5) and whether participant students would be able and willing to use a number of affordances in the way they were intended (Section 
Table 4. The three strands of IC competence, six objectives of IC teaching and assessment and three assessment techniques used in the present study.

1) Knowledge (cognitive): of social groups and their products and practices in one's own and in one's interlocutor's country, and of the general processes of societal

and individual interaction.

Objectives (knowledge of/about):

a) The processes and institutions of socialisation in one's own and in one's interlocutor's country.

b) Institutions, and perceptions of them, which impinge on daily life within one's own and in one's interlocutor's country and which conduct and influence relationships between them.

Assessment technique: CAT

Close-ended questions: true-false, multiple choice, and matching

2) Attitudes (Affective): curiosity \& openness, readiness to suspend disbelief about other cultures and belief about one's own.

Objectives:

c) Willingness to seek out or take up opportunities to engage with otherness in a relationship of equality, distinct from seeking out the exotic or to profit from others.

d) Interest in discovering other perspectives on interpretation of familiar and unfamiliar phenomena both in one's own and in other cultures and cultural practices.

Assessment technique: CMT

Close-ended questions: multiple choice

3) Skills (behavioral)

- Of interpreting \& relating (savoir comprendre): ability to interpret a document or event from another culture, to explain it and relate it to documents or events from one's own.

- Of discovery \& interaction (savoir apprendre/faire): ability to acquire new knowledge of a culture and cultural practices and the ability to operate knowledge, attitudes, and skills

Objectives (ability to):

e) Identify areas of misunderstanding and dysfunction in an interaction and explain them in terms of each of the cultural systems present.

f) Elicit from an interlocutor the concepts or values of documents or events and develop an explanatory system susceptible of application to other phenomena.

Assessment technique: CIT

Close-ended questions: multiple choice

2.2.6). In fact, and for the sake of ease of use, the educational intervention sought to present the teaching content and learning opportunities using conventional classroom tools and techniques. Classroom tools included whiteboard, PowerPoint presentations, and printouts. Classroom techniques included seating arrangements, learner groupings, facilitation of tasks, opportunities for experiential learning, increased motivation and engagement, and feedback. The techniques and activities (Section 2.2.5) developed to facilitate the learning process included the CAT, CMT, and CIT described earlier.

An assessment framework was also planned in alignment with the various 
learning processes described above. In brief, each assessment task encompassed a task description (the assignment); a specific list of the dimensions, elements, or aspects to look for in a student's production (criteria) (Section 2.3.1); a scoring guide (levels of performance, possibly in the form of grades) that identify students' level of mastery within each criterion (scale) (Section 2.3.2); and statements that describe the characteristics associated with each dimension and level of performance (descriptors) (Section 2.3.3). The three methods of assessment described earlier (Section 2.3.4), were employed, namely Assessment for learning, assessment as learning, and assessment of learning. Various assessment tools and instruments were planned, including student diaries, tests, and interviews. Three assessment techniques (Section 2.3.5) were adopted, namely CAT, CMT, and CIT.

\subsection{Quality Evaluation Issues}

The instructional and assessment materials used in the present study were submitted to experts in the field for evaluation, particularly in terms of reliability and validity, prior to implementation. In line with Borg \& Gall (1989), validity evaluation included face validity and content validity. The materials were assessed for face validity by 2 experienced statisticians. The criteria included language appropriacy, clarity, unambiguity, spelling, structure, and formatting. Content validity was assessed by 4 experienced EFL practitioners from both language and cultural studies backgrounds. The experts checked the materials with reference to Byram's theoretical framework on Teaching and Assessing Intercultural Communicative Competence (Byram, 1997, pp. 57-64). Feedback from the experts helped ensure that the research materials were eligible and properly prepared to achieve the objectives of the study. To the author's knowledge, the INCA's assessment framework adopted in this work has not been validated as an assessment tool yet. Nevertheless, being anchored in Byram's multidimensional IC model, the INCA (2004) project seems appropriate to the Tunisian EFL context. Byram's model has also been adopted in several assessment projects, including the INCA project. The latter combines quantitative and qualitative assessment instruments, including questionnaires, scenarios, and role plays. Although no research studies have so far reported on results using the INCA model, several reports have provided ample support for the reliability and validity of the scenarios, including the CAT, CMT and CIT, as assessment instruments. Furthermore, special care was given by the researcher to the criteria of test quality, namely "validity" and "authenticity", which relate to test content; "reliability", which relates to test scores; "clarity of purpose and impact", which relates to the potential test effects on the test-takers; and "practicality", which relates to test administration (Sercu, 2004: pp. 79-87).

The results of the present study yielded into a comprehensive intercultural training course that included attainable goals, achievable learning outcomes, realizable learning objectives, conducive learning experiences, along with clear assessment criteria, scales, descriptors, methods, and tools for gauging desired 
learning outcomes. The validation of the effectiveness of the training course in enhancing IC learning is pending on its implementation and evaluation, particularly in terms of its effectiveness in fostering IC development in EFL learners, a topic that will be reported on in an upcoming paper by the author (Smaoui, forthcoming). Reflections on the training course impacts using a Strengths, Weaknesses, Opportunities, and Threats (SWOT) analysis could also be conducive to bridging potential gaps between theory and implementation.

\section{Conclusion}

Despite the growing flow of research on the intercultural dimension in EFL education worldwide, relatively little attention has been given to the significance of this dimension to curriculum, course, and materials design in the Tunisian EFL context. Teaching EFL in this time of change requires new teaching materials that take the new trends of internationalization, of multilingualism and multiculturalism, of local and global identities, and of traditional physical and contemporary virtual learning environments into account. The general tendency seems to encourage teachers to take an informed global approach to EFL teaching wherein they think globally and act locally. The process entails the rethinking of the whole educational process to ensure the alignment of various interrelated and synergistic aspects, namely the 1) goals, 2) content, 3) instructional design, 4) tasks, 5) roles 6) affordances, and 7) assessment (Biggs, 1996; Biggs \& Moore, 1993). Considering the scarcity of data on these issues within the Tunisian higher education EFL context, the present study aimed to explore the opportunities and challenges of developing an intercultural training course consisting of teaching materials that basically employ three types of teaching techniques, namely the cultural awareness technique (CAT), critical incident technique (CIT) and cultural misunderstanding technique (CMT). Although in some instances the present study might have focused on a number of dimensions that serve its research purposes, it has, in other instances, widened the scope of discussion to include the implications for further research on teaching materials development in the local and global EFL contexts. The present work is particularly interesting for it could form a critical foundation for further research on the intercultural dimension in higher education EFL contexts and a tentative blueprint for future attempts to develop and design intercultural EFL training courses and teaching materials. Furthermore, the results of this study have important educational and pedagogical implications. They imply that the EFL teaching and research community has quite a lot of work to do in the route to develop a strategic approach to IC teaching and assessment. It seems imperative that the EFL community formulate a structured framework through which it can 1) develop a clear understanding of the IC construct, keeping in mind that there could be multiple definitions of IC from a variety of academic disciplines, 2) define IC and explicitly include it as a major EFL program learning outcome (PLO), and 3) develop a systematic approach to refer to IC as a major EFL course learning outcome (CLO). A strategic plan for teacher training and continuous professional 
development in IC teaching and assessment is also an equally pressing need. TPACK awareness and ICT competences would also enable teachers to enact interculturality and use educational technologies as tools to facilitate its communication to their students.

\section{Acknowledgements}

The present study is in part a partial rework and analysis of the data presented in my master's thesis and in another an extension of that earlier work into publishable research articles. The author would like to express his sincere gratitude to all those who helped conduct this research, my colleagues in the higher education institutes, and all students who participated in the study.

\section{Conflicts of Interest}

The author declares no conflicts of interest regarding the publication of this paper.

\section{References}

Abid, N. (2018). Developing National and Intercultural Identities in Tunisian EFL Classes: A Study of English Textbooks, Teachers and Learners Attitudes. In M. Guirat (Ed.), Politics and Poetics of Belonging (pp. 169-196). Newcastle: Cambridge Scholars Publishing.

Abid, N., \& Moalla, A. (2020). The Promotion of the Good Intercultural Speaker through Intercultural Contacts in a Tunisian EFL Textbook. Language and Intercultural Communication, 20, 37-49. https://doi.org/10.1080/14708477.2019.1676765

ACTFL (1996). Standards for Foreign Language Learning. Alexandria, VA: ACTFL.

Anderson, L. W., \& Krathwohl, D. R. (2001). A Taxonomy for Teaching, Learning, and Assessing: A Revision of Bloom's Taxonomy of Educational Objectives. New York: Longman.

Arfi, I., \& Hannachi, A. (2016). Towards Intercultural Communicative Competence in EFL Teaching at the Tunisian University. International Journal of English Language, Literature and Humanities, 4, 400-414.

Baxter, J., \& Ramsey, S. (1996). Improvising Critical Incidents. In N. H. Seelye (Ed.), EXperiential Activities for Intercultural Learning (Vol. 1, pp. 211-218). Yarmouth, ME: Intercultural Press.

Beaven, A., \& Livatino, L. (2012) CEFcult: Online Assessment of Oral Language Skills in an Intercultural Workplace. Procedia-Social and Behavioral Sciences, 34, 25-28. https://doi.org/10.1016/j.sbspro.2012.02.006

Biggs, J. B. (1996). Enhancing Teaching through Constructive Alignment. Higher Education, 32, 347-364. https://doi.org/10.1007/BF00138871

Biggs, J. B. (2003). Aligning Teaching and Assessment to Curriculum Objectives. Imaginative Curriculum Project, LTSN Generic Centre.

Biggs, J. B., \& Tang, C. (2011). Teaching for Quality Learning at University (Fourth ed.). London: McGraw-Hill.

Biggs, J., \& Moore, P. (1993). The Process of Learning (3rd ed.). New York: Prentice Hall.

Bloom, B. S. (1956). Taxonomy of Educational Objectives: The Classification of Educational Goals. New York: Longmans, Green. 
Borg, W. R., \& Gall, M. D. (1989). Educational Research: An Introduction (5th ed.). New York: Longman.

Boyle, T., \& Cook, J. (2004). Understanding and Using Technological Affordances: A Commentary on Conole \& Dyke. ALT-J, 12, 295-299. https://doi.org/10.3402/rlt.v12i3.11260

Briggs, L. J. (1977). Instructional Design: Principles and Applications. Englewood Cliffs, NJ: Educational Technology Publications.

Briggs, L. J., Gustafson, K. L., \& Tillman, M. H. (1991). Instructional Design, Principles and Application. Englewood Cliffs, NJ: Educational Technology Publications.

Brindley, G. (1984). Needs Analysis and Objective Setting in the Adult Migrant Education Program. Sydney: NSW Adult Migrant Education Service.

Brislin, R. W. (1995). The Culture-General Assimilator. In S. M. Fowler, \& M. G. Mumford (Eds.), Intercultural Sourcebook: Cross-Cultural Training Methods (Vol. 1, pp. 169-177). Yarmouth, ME: Intercultural Press.

Brown, J. D. (1995). The Elements of Language Curriculum: A Systematic Approach to Program Development. Boston, MA: Heinle ELT.

Brown, J. D. (2009). Foreign and Second Language Needs Analysis. In M. H. Long, \& C. J. Doughty (Eds.), The Handbook of Language Teaching (269-293). Hoboken, NJ: Wiley-Blackwell.

Byram, M. (1989). Cultural Studies and Foreign Language Education. Clevedon: Multilingual Matters.

Byram, M. (1997). Teaching and Assessing Intercultural Communicative Competence. Clevedon: Multilingual Matters.

Chastain, K. (1988). Teaching Culture: Developing Second Language Skills. Chicago, IL: Harcourt Brace Jovanorich, Publishers.

Chen, G. M., \& Starosta, W. J. (1996). Intercultural Communication Competence: A Synthesis. Communication Yearbook, 19, 353-384.

https://doi.org/10.1080/23808985.1996.11678935

Council of Europe (CEFR) (2001). Common European Framework of Reference for Languages: Learning, Teaching, Assessment. Cambridge: Cambridge University Press.

Cuenat, M. E., Cole, J., Muller, C., Szczepanska, A., Bleichenbacher, L., \& Wolfer, B. (2015). Plurilingual and Intercultural Learning through Mobility. Practical Resources for Teachers and Teacher Trainers. Strasbourg: Council of Europe (European Centre for Modern Languages).

Cushner, K., \& Brislin, R. (1996). Intercultural Interactions: A Practical Guide (2nd ed.). Thousand Oaks, CA: Sage.

Deardorff, D. K. (2006). Identification and Assessment of Intercultural Competence as a Student Outcome of Internationalization. Journal of Studies in International Education, 10, 241-266. https://doi.org/10.1177/1028315306287002

Deardorff, D. K. (2009). The SAGE Handbook of Intercultural Competence. Thousand Oaks, CA: SAGE.

Doering, A., Miller, C., \& Veletsianos, G. (2008). Adventure Learning: Educational, Social and Technological Affordances for Collaborative Hybrid Distance Education. The Quarterly Review of Distance Education, 9, 249-265.

Earl, L. (2003). Assessment as Learning: Using Classroom Assessment to Maximize Student Learning. San Francisco, CA: Corwin Press.

Fantini, A. E. (1997). New Ways in Teaching Culture. Alexandria, VA: TESOL. 
Fantini, A., \& Tirmizi, A. (2006). Exploring and Assessing Intercultural Competence. World Learning Publications.

Feng, A., \& Byram, M. (2002). Authenticity in College English Textbooks-An Intercultural Perspective. RELC Journal, 33, 58-84. https://doi.org/10.1177/003368820203300203

Fenner, A. B., \& Newby, D. (2000). Approaches to Materials Design in European Textbooks: Implementing Principles of Authenticity, Learner Autonomy, Cultural Awareness. Strasbourg-Graz: Council of Europe Publishing, ECML.

Gagne, R. M., Briggs L. J., \& Wager, W. W. (1992). Principles of Instructional Design (4th ed.). Fort Worth, TX: Harcourt Brace College Publishers.

Hammer, M. R., Bennett, M. J., \& Wiseman, R. (2003). The Intercultural Development Inventory: A Measure of Intercultural Sensitivity. International Journal of Intercultural Relations, 27, 421-443. https://doi.org/10.1016/S0147-1767(03)00032-4

Hermessi, T. (2016). Teacher Cognition on the Place of Culture in English Education in Tunisia. International Journal of Society, Culture \& Language, 4, 105-118.

Hermessi, T. (2017). The Place of Culture in English Education in Tunisia. In C. Coombe, \& S. Hidri (Eds.), Perspectives on Evaluation in the Arab World (203-220). New York: Springer Publishing Company. https://doi.org/10.1007/978-3-319-43234-2 12

Horchani-Elmadssia, T., \& Hosni, M. (2012). Impact of Intercultural Training on the Development of Intercultural Competences. European Journal of Business and Social Sciences, 1, 35-47.

Huber-Kriegler, M., Lazar, I., \& Strange, J. (2003). Mirrors and Windows-An Intercultural Communication Textbook. Graz: European Centre for Modern Languages, Council of Europe Publishing.

Hutchinson, T., \& Waters, A. (1987). English for Specific Purposes: A Learner-Centered Approach. Cambridge: Cambridge University Press.

https://doi.org/10.1017/CBO9780511733031

INCA Project Team (2004). INCA Assessor Manual. INCA Project, Leonardo da Vinci Program.

Kelley, C., \& Meyers, J. (1992). The Cross-Cultural Adaptability Inventory. Minneapolis, MN: National Computer Systems, Inc.

Kramsch, C. (1993). Context and Culture in Language Teaching. Oxford: Oxford University Press.

Mason, J. (2010). The Effects of Different Types of Materials on the Intercultural Competence of Tunisian University Students. In B. Tomlinson, \& H. Masuhara (Eds.), Research for Materials Development in Language Learning: Evidence for Good Practice (pp. 67-82). London: Continuum.

McKay, S. (2003). Toward an Appropriate EIL Pedagogy: Re-Examining Common ELT Assumptions. International Journal of Applied Linguistics, 13, 1-22. https://doi.org/10.1111/1473-4192.00035

Paige, M. R., Jorstad, H., Siaya, L., Klein, F., \& Colby, J. (1999). Culture Learning in Language Education: A Review of the Literature. In R. M. Paige, D. L. Lange, \& Y. A. Yeshova (Eds.), Culture as the Core: Integrating Culture into the Language Curriculum (pp. 47-113). Minneapolis, MN: University of Minnesota.

Prechtl, E., \& Davidson-Lund, A. (2007). Intercultural Competence and Assessment: Perspectives from the INCA Project. In H. Kotthoff, \& H. Spencer-Oatey (Eds.), Handbook of Intercultural Communication (pp. 467-490). Berlin and New York: Mouton de Gruyter. 
Pusch, M. D. (1996). Framework for Using Critical Incidents. In N. H. Seelye (Ed.), Experiential Activities for Intercultural Learning (Vol. 1, pp. 207-209). Yarmouth, ME: Intercultural Press.

Rahal, A. (2017). Cultural Problems in Teaching and Learning of English as a Foreign Language in Tunisia. In S. Ambreen, \& G. K. Syed (Eds.), Student Culture and Identity in Higher Education (pp. 257-274). Hershey, PA: IGI Global. https://doi.org/10.4018/978-1-5225-2551-6.ch015

Risager, K. (1991). Cultural Studies and Foreign Language Teaching after World War II: The International Debate as Received in the Scandinavian Countries. In D. Buttjes, \& M. Byram (Eds.), Mediating Languages and Cultures: Towards an Intercultural Theory of Foreign Language Education (pp. 33-46). Clevedon: Multilingual Matters.

Seelye, H. N. (1996). Experiential Activities for Intercultural Learning (Vol. 1). Yarmouth, ME: Intercultural Press.

Seelye, H. N. (1997). Teaching Culture Strategies for Intercultural Communication. Lincolnwood, IL: National Textbook Company.

Sercu, L. (2002). Autonomous Learning and the Acquisition of Intercultural Communicative Competence: Some Implications for Course Development. Language, Culture and Curriculum, 15, 61-74. https://doi.org/10.1080/07908310208666633

Sercu, L. (2004). Assessing Intercultural Competence: A Framework for Systematic Test Development in Foreign Language Education and Beyond. Intercultural Education, 15, 73-89. https://doi.org/10.1080/1467598042000190004

Sercu, L. (2005). Teaching Foreign Languages in an Intercultural World. In L. Sercu (Ed.), Foreign Language Teachers and Intercultural Competence: An International Investigation (Vol. 10, pp. 1-18). Bristol: Multilingual Matters. https://doi.org/10.21832/9781853598456

Sinicrope, C., Norris, J., \& Watanabe, Y. (2007). Understanding and Assessing Intercultural Competence: A Summary of Theory, Research, and Practice. Second Language Studies, 26, 1-58.

Skopinskaja, L. (2003). The Role of Culture in Foreign Language Teaching Materials: An Evaluation from an Intercultural Perspective. In I. Lazar (Ed.), Incorporating Intercultural Communicative Competence in Language Teacher Education (pp. 39-67). Strasbourg: European Centre for Modern Languages, Council of Europe.

Smaoui, A. (2020). The Intercultural Dimension in the Tunisian Higher Education EFL Context: Teacher and Student Perceptions and Practices. International Journal of Humanities and Cultural Studies, 6, 66-99.

Stiggins, R. J. (2001). Student-Involved Classroom Assessment (3rd ed.). Upper Saddle River, NJ: Merrill-Prentice Hall.

Storti, C., \& Bennhold-Samaan, L. (1997). Culture Matters: The Peace Corps Cross Cultural Workbook. Washington DC: Peace Corps (U.S.).

Tomlinson, B. (2008). English Language Learning Materials-A Critical Review. London: Continuum.

Tomlinson, B. (2010). Principles for Effective Materials Development. In N. Harwood (Ed.), English Language Teaching Materials: Theory and Practice (pp. 80-108). Cambridge: Cambridge University Press.

Tomlinson, B. (2012). Materials Development for Language Learning and Teaching. Language Teaching, 45, 143-179. https://doi.org/10.1017/S0261444811000528

Tomlinson, B., \& Masuhara, H. (2010). Research for Materials Development in Language Learning: Evidence for Best Practice. London: Continuum. 
Verjans, S., Kamakshi, R. K., Lut, B., Lutgart, D., \& Jan, V. M. (2011). D4.1. CEFcult Framework and Methodology. CEFcult Project Deliverables, Brussels: European Commission, Education, Audiovisual \& Culture Executive Agency.

West, R. (1997). Needs Analysis: State of the Art. In R. Howard, \& G. Brown (Eds.), Teacher Education for LSP (pp. 68-79). Clevedon: Multilingual Matters.

Young, P. A. (2009). Instructional Design Frameworks and Intercultural Models. Hershey, PA: Information Science Reference. https://doi.org/10.4018/978-1-60566-426-2 